\title{
Budesonide enemas for topical therapy of ulcerative colitis
}

\author{
P RUTGEERTS, MD
}

\begin{abstract}
Budesonide is a nonhalogenated glucocorticosteroid that is very suitable for topical therapy in left-sided colitis because it has a high ratio of topical to systemic activity. Although it is absorbed, it is very rapidly metabolized by the liver (first pass metabolism). It does not suppress the hypothalamic-pituitary axis. Budesonide has been shown to be more effective than placebo and prednisolone enemas for the treatment of left-sided ulcerative colitis. Can J Gastroenterol $1990 ; 4(7): 415-416$
\end{abstract}

Key Words: Budesonide, Topical therapy, Ulcerative colitis

\section{Les lavements de budésonide et le traitement local de la colite ulcéreuse}

RESUME: Le budésonide est un glucocorticostéroïde non halogéné qui est particulièrement adapté au traitement topique de la colite à prédominance gauche parce que son action topique permet l'obtention d'une concentration élevée tout en minimisant les effets systémiques. Bien qu'absorbé, il est très rapidement métabolisé par le foie (métabolisme de premier passage). Il ne freine pas l'axe hypothalamo-hypophysaire. Le budésonide a prouvé son efficacité supérieure à celle du placebo et des lavements à base de prednisolone dans le traitement de la colite ulcéreuse à prédominance gauche.

$\mathrm{T}$ OPICAL THERAPY IN INFLAMMAtory bowel disease (IBD) is very attractive, but possible only in the presence of distal rectosigmoidal inflammation. Moreover, topically administered drugs are also absorbed to a great extent and absorption may depend on the degree of inflammation at the level of the rectosigmoid mucosa. Corticosteroid enemas and foams, ie, hydrocortisone and prednisolone, were first choice drugs in the treatment of distal ulcerative rectosigmoiditis until 5-aminosalicylic acid (5-ASA) enemas and suppositories were shown to be effective.

The main disadvantage of topical corticosteroid therapy is the important side effects secondary to high systemic exposure secondary to absorption. Chronic treatment with enemas containing corticosteroids may produce suppression of the hypothalamicpituitary axis. Corticosteroids, however, could become first choice drugs if the preparation used had high therapeutic efficacy and no systemic side effects due to either poor absorption or large first pass metabolism. One candidate molecule is budesonide.

\section{CHEMISTRY AND FORMULATION}

Budesonide is a nonhalogenated glucocorticosteroid that is structurally related to 16-alpha-hydroxyprednisolone. It has a molecular weight of 430.5
Daltons and is a mixture of the $22 \mathrm{R}$ and $22 \mathrm{~S}$ epimers (1). Budesonide is not sufficiently stable in dilute aqueous solution, and is therefore delivered in a tablet to be added to the vehicle immediately before administration of the enema. The solubility of budesonide in water in the present formulation is approximately $35 \%$ (2).

Budesonide enema $(0.02 \mathrm{mg} / \mathrm{mL})$ therefore consists of two components, a $2.3 \mathrm{mg}$ tablet and $115 \mathrm{~mL}$ of vehicle. The enema is prepared by combining the tablet and vehicle before administration. The tablet is allowed to disintegrate for $1 \mathrm{~min}$ and thereafter the contents are vigorously shaken.

\section{CLINICAL PHARMACOLOGY}

In animals budesonide has a high ratio of topical to systemic activity compared with reference steroids such as beclomethasone dipropionate, flunisolide and triamcinolone acetonide (3). This high local anti-inflammatory activity was also confirmed in humans using a skin vasoconstriction assay (4). Between two and four times less systemic activity is found after inhalation of budesonide than after beclomethasone dipropionate (5). Budesonide is metabolized very rapidly in the liver. Plasma concentrations of budesonide after rectal application of $2 \mathrm{mg}$ budesonide are very low, with a peak concentration after 2 to $4.5 \mathrm{~h}$ of the order of 1.0 to $3.5 \mathrm{nmol} / \mathrm{L}$. The bioavailability has been calculated to be about $13 \%$ of a dose given rectally, with evidence of extensive first pass metabolism (2).

The systemic effect of different doses of budesonide, measured as depression 
of endogenous cortisol production, has been assessed in healthy volunteers. A dose of $2 \mathrm{mg}$ or less does not significantly depress plasma cortisol levels when it is given as an enema once daily.

Budesonide is eliminated via the oxidative liver enzymes. A number of drugs as well as liver failure may thus decrease the metabolism of budesonide and increase systemic levels. The two major metabolites of budesonide are 6 beta-hydroxybudesonide and 16-alphahydroxyprednisolone. It has been shown that these metabolites have much less glucocorticoid activity (less than $1 \%$ ) than budesonide.

The volume of distribution of budesonide is comparatively large ( 301 L), indicative of wide tissue distribution. Budesonide has been shown to be extensively bound to plasma proteins $(88.3 \%)$ with negligible binding to transcortin. The relatively short elimination half-life $(2.8 \mathrm{~h})$ and high plasma clearance $(83.7 \mathrm{~L} / \mathrm{h})$ highlight the rapid systemic elimination of budesonide (6).

Only trace amounts of budesonide are excreted unchanged in the urine.

\section{TOXICOLOGY}

The acute toxicity of budesonide in animal experiments was low and of the same order of magnitude and type as the reference glucocorticoids (2).

The general toxic effects of budesonide are similar to those observed after administration of other glucocorticoids, eg, decreased body weight gain and atrophy of lymphoid tissues and adrenal cortex. In many cases the effects of budesonide were found to be less severe than those elicited by reference corticosteroids. In humans, budesonide-induced skin rash was observed in one patient in a dose-finding study. Effects on reproduction and mutagenic potential of budesonide tend to be less severe than those obtained with reference compounds.

\section{CLINICAL EXPERIENCE}

A steroid for local treatment of IBD should have high intrinsic glucocorti- coid activity, be readily absorbed by the target organ, undergo little or no local biotransformation and be rapidly inactivated once absorbed. Budesonide fulfills all of these requirements.

The only published study is a comparison of budesonide enemas with prednisolone enemas (7). In this study 64 patients ( 27 men and 37 women), mean age 42 years (range 19 to 65 ) with active distal ulcerative colitis were included. Thirty-one of them were allocated to budesonide enema and 33 to prednisolone enema treatment. Eight patients dropped out after two weeks: three in each group because of complete remission and two in the prednisolone group because of treatment failure. Although symptoms improved greatly in both treatment groups the decrease in frequency of bloody stools was significantly greater in the budesonide group compared with the prednisolone group at two and four weeks.

After two weeks of treatment significantly more patients were healed or improved endoscopically in the budesonide group ( 29 of 31 ) than in the prednisolone group (22 of 33) $(\mathrm{P}=0.018)$. By four weeks the differences were not significant (budesonide 26 of 29; prednisolone 21 of 28). Patients taking budesonide reduced their symptom scores more quickly than those treated with prednisolone.

There was a very good correlation between endoscopic classification and histologic findings, which were evaluated in a blinded manner.

Histologically there was also a significantly better improvement in the budesonide group at two weeks (20 of 24) and four weeks (21 of 23) compared to prednisolone (nine of 23; $\mathrm{P}=0.0048$ ) and ( 12 of $22 ; \mathrm{P}=0.014)$. Prednisolone enema significantly depressed the levels of plasma cortisol at both two and four weeks, but budesonide did not. There were no reported side effects in either of the groups. Two additional trials have been completed but have not yet been published. In a placebo controlled trial, Danielson (8) showed that budesonide $(2 \mathrm{mg} / 100 \mathrm{~mL})$ was superior to placebo for therapy of severe distal ulcerative colitis or proctitis. A dose response study (9) has also been carried out using enemas containing 1 , 2 or $4 \mathrm{mg}$ of budesonide versus prednisolone $25 \mathrm{mg}$ enemas (9). Clinical efficacy was shown but no clear dose response was observed.

\section{CONCLUSION}

Budesonide is a very promising drug and seems suitable for topical therapy of left-sided colitis. It is very efficacious in healing left-sided sedative colitis, with no side effects and no suppression of the hypothalamic-pituitary axis. A comparison trial with 5-ASA enemas is currently underway.

\section{REFERENCES}

1. Thalen A, Brattsand R. Synthesis and anti-inflammatory properties of budeso. nide, a new nonhalogenated glucocorticoid with high local activity.

Arzneimittelforschung 1982;29:1687. 90.

2. Data on file, AB Draco.

3. Brattsand R, Thalen A, Roempke K, Källström L, Gruvstad E. Influence of $16 \alpha, 17 \alpha$-acetal substitution and steroid nucleus fluorination on the topical to systemic activity ratio of glucocorticoids. J Steroid Biochem 1982;16:779-86.

4. Gruvstad E, Bengtsson A. A comparison of a new steroid, budesonide, with other topical corticosteroids in the vasoconstriction assay. Drugs Exp Clin Res 1980;6:385-90.

5. Johansson S-A, Andersson K-E, Brattsand R, Gruvstad E, Hedner P. Topical and systemic glucocorticoid potencies of budesonide and beclomethasone dipropionate in man. Eur ] Clin Pharmacol 1982;22:523-9.

6. Ryrfeldt A, Andersson P, Edsbäcker S, Tönnesson M, Davies D, Pauwels R. Pharmacokinetics and metabolism of budesonide, a selective glucocorticoid. Eur J Respir Dis 1982;63(Suppl 122): 86-95.

7. Danielsson A, Hellers G, Lyrenäs E, et al. A controlled randomized trial of budesonide versus prednisolone retention enemas in active distal ulcerative colitis. Scand J Gastroenterol 1987;22:987-92.

8. Danielsson A. Clinical study 1990.

9. Clinical study. AB Draco 1990. 


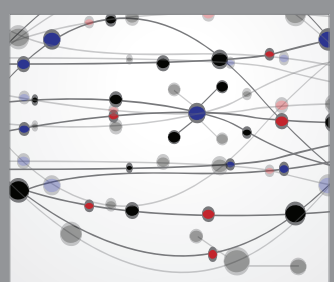

The Scientific World Journal
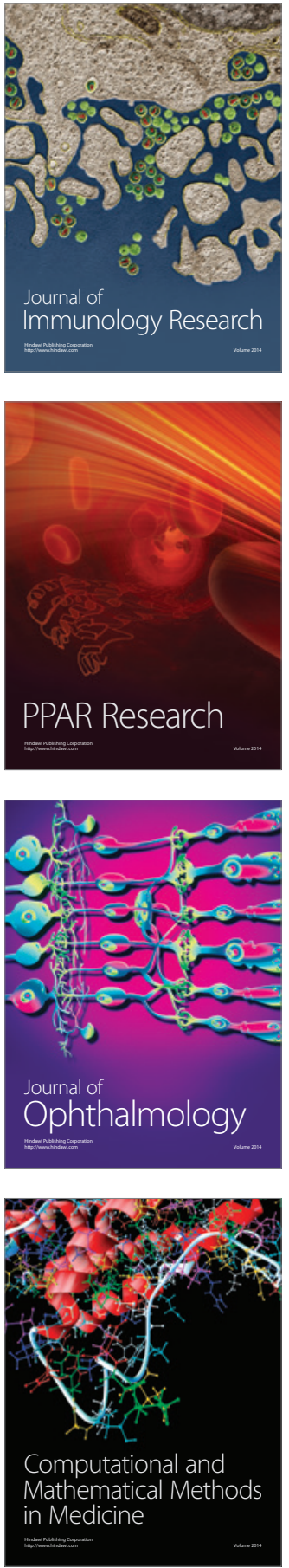

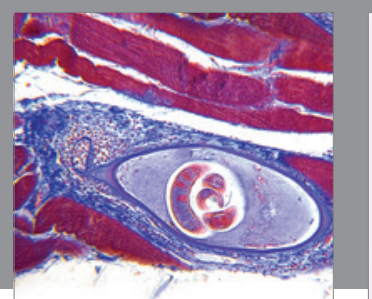

Gastroenterology Research and Practice

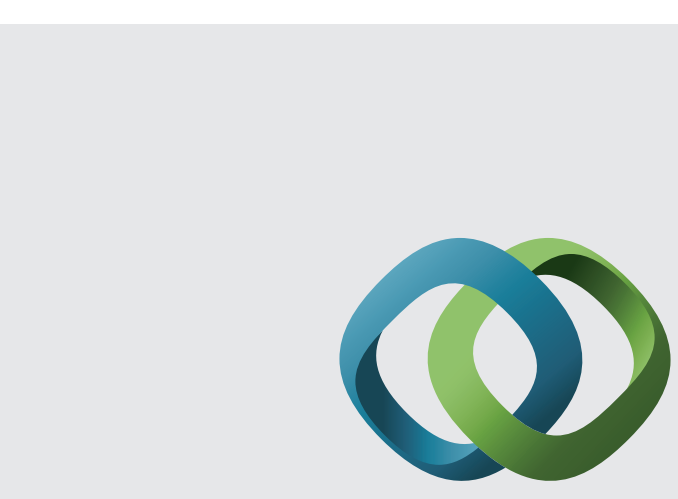

\section{Hindawi}

Submit your manuscripts at

http://www.hindawi.com
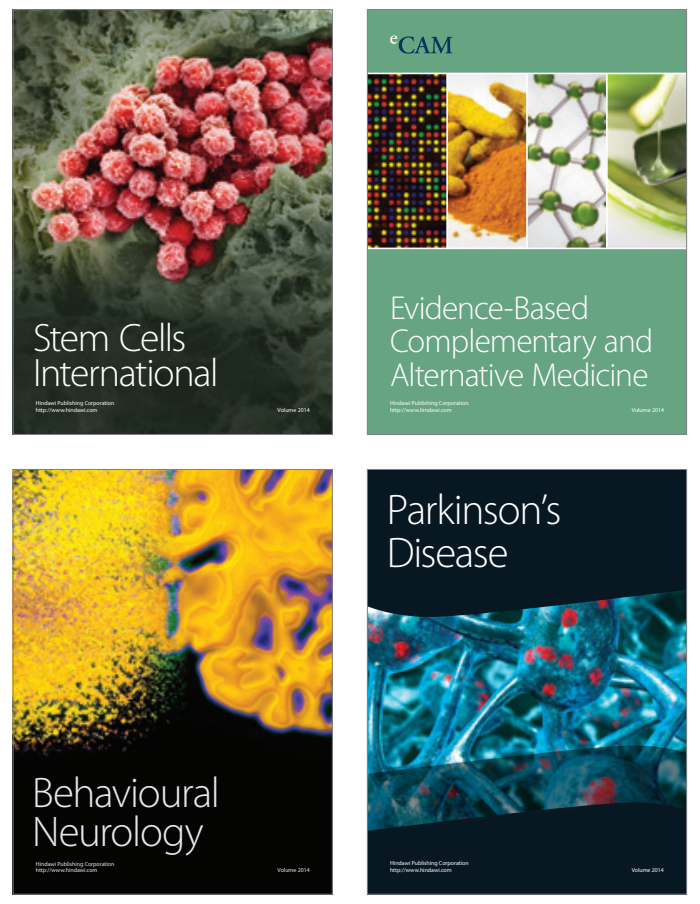
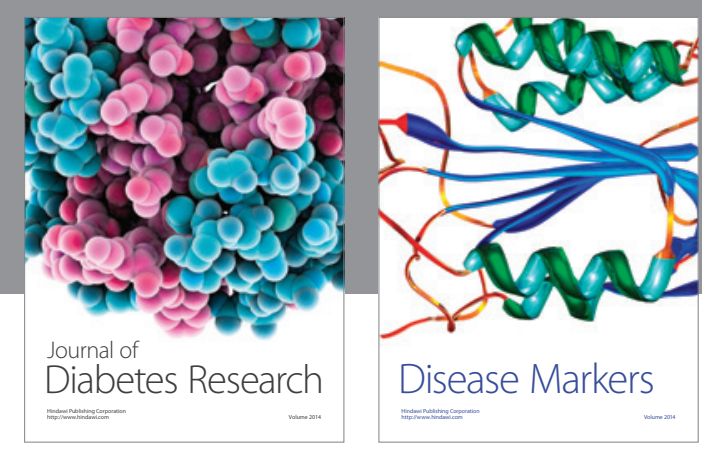

Disease Markers
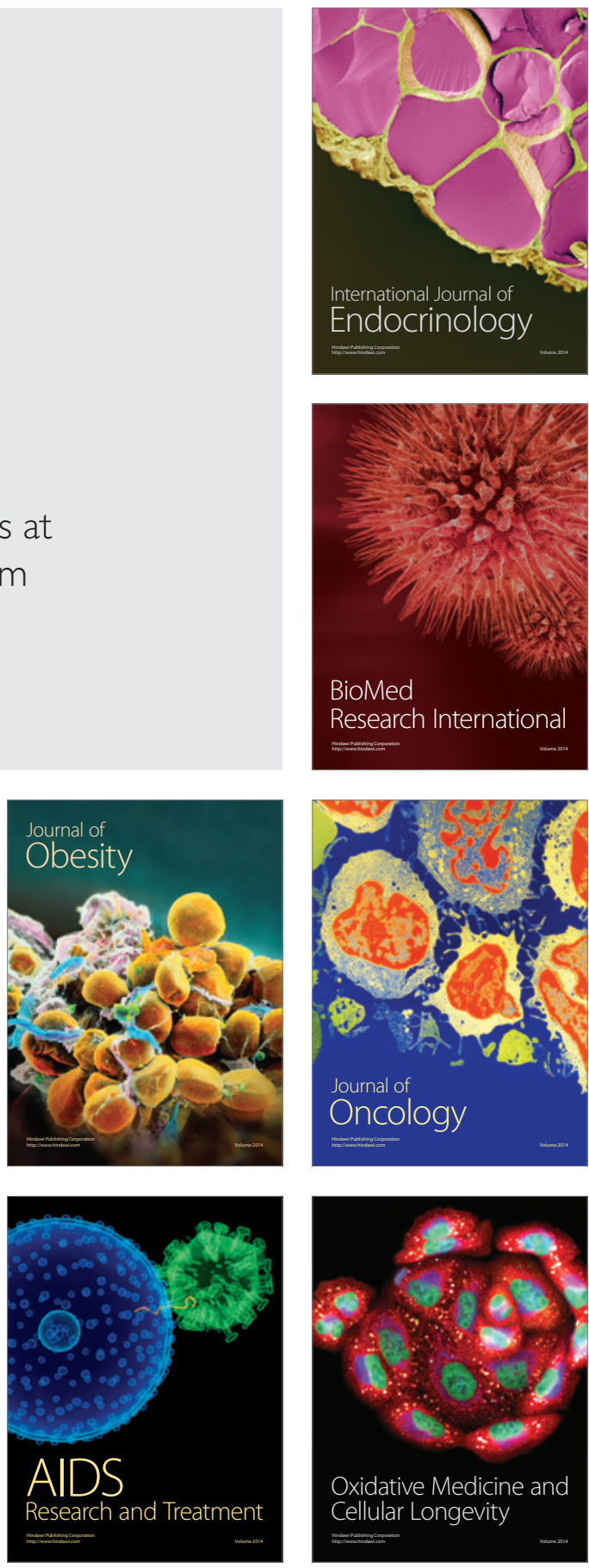